\title{
Contribution of Human Resource Development to Organisations: A Case Study of Asuogyaman District Assembly
}

\author{
George Asamoah \\ Department of Hospitality and Tourism Management, Marshall's University College, Accra, Ghana \\ Email address: \\ asmogat@yahoo.com
}

\section{To cite this article:}

George Asamoah. Contribution of Human Resource Development to Organisations: A Case Study of Asuogyaman District Assembly. Journal of Human Resource Management. Vol. 4, No. 4, 2016, pp. 32-36. doi: 10.11648/j.jhrm.20160404.11

Received: June 7, 2016; Accepted: June 15, 2016; Published: June 30, 2016

\begin{abstract}
Human resource development is currently as an important strategic approach to improved productivity, efficiency and profitability. However, the level of human resource development which should be the central driving force in the achievement of organisational goals and economic development in Ghana is not encouraging and should be given the needed boost by building the knowledge, skills, working abilities and innate capacities of all the people across the society. This study therefore examines the potential contributions of human resource development to organisations in Ghana in order to make recommendations that will ensure that the required human resource needs are provided. To do this, Asuogyaman District Assembly was selected as a case study. Both primary and secondary data were collected and analyzed. The study found out that $72.5 \%$ of staff in the organisation was involved in a training programme. Most staff occasionally had their training needs assessed. Performance management/appraisal and human resource planning are promoted. Human resource development contributes to increased productivity and builds manpower abilities. Based on the findings, it is recommended among others things that; all organisations should establish a human resource development policy that will encourage systematic learning, performance and change as a means to increase productivity.
\end{abstract}

Keywords: Human Resource, Training and Development, Organisation, Productivity, Efficiency

\section{Introduction}

Human resource development (HRD) is said to be all activities designed to enhance people's capacity in order to perform on the job. This can be traced directly to early apprenticeship training programs in the $18^{\text {th }}$ century. During this time, small shops operated by skilled artisans produced virtually all household goods such as furniture, clothing and shoes to meet a growing demand for their products (Noe et al., 2014). The specific objectives of HRD are to develop the intellectual capital and promote organizational, team and individual learning by creating a learning culture- an environment in which employees are encouraged to learn and develop and in which knowledge is managed systematically (Jennine, 2005). Human Resource policies have to take into account individual aspirations and needs as well as the importance of increasing employability, outside and within the organization.
The need for HRD has become even stronger as organizations grapple within the challenges presented by a fast paced, highly dynamic, increasingly global economy to compete and thrive, many on, training and development as an important and effective part of their strategy. For example, it has been estimated that education and training programmes accounted for as much as $26 \%$ of the increase in U.S production capacity between 1929 and 1982 (Gainer, 1989).

According to Acheampong (2006), Human Resource consists of the productive contribution of labour to the production process and therefore in order to improve the quality of labour to be productive, there is the need to undertake investment in human resources. This investment will encapsulate both the explicit and implicit costs involved in the acquisition of education, skills and experience, through training and development among other things. In such a process, human capital is developed and it increases productivity. 
As described by Harrison (2000), HRD arises from a clear vision about people's abilities and potentials that operates within the overall strategic framework of the business. HRD takes a broad and long term view about how policies and practices can support the achievement of business strategies. It is business-led and the learning and development strategies that are established as part of the overall strategic HRD approach flow from business strategies and have a positive role in helping to ensure that the business attains its goals.

The fundamental aim of HRD is to enhance resource capability in accordance with the belief that human capital in an organization is a major source of competitive advantage. It is therefore about ensuring that the right quality people are available to meet present and future needs, which is achieved by producing a coherent and comprehensive framework for developing people

As defined by Kumar (1991), HRD in an organization is concerned with the development of human resources and helping them to acquire new capabilities required for the achievement of the corporate as well as the individual goals. Human Resource Development believes that individuals in an organization have unlimited potentials for growth and development and that their potentials can be developed and multiplied through appropriate and systematic efforts. Given the opportunities and by providing the right type of climate in the organization, individuals can be helped to give full expression of their potentials, contributing to the achievement of the goals of the organization and thereby ensuring optimization of human resources (Nadler and Wiggs, 1986).

In effect, the level of HRD is the central driving force in the achievement of economic development. Many economists believe that the key asset that propelled their selfsustained economic growth and development is not their physical capital but the body of knowledge amassed by empirical science coupled with the ability to train and equip the population to use the knowledge effectively. All these suggestions bring Human Resource Planning to bear on organisations to ensure that the right people are present to manage and operate the organisation in accordance with its objectives (Dyer, 2006).

The purpose of the study is to examine the numerous contributions that HRD has made to organizations. The specific, objectives are: determining the contribution of HRD to increase productivity in organizations, the contributions of Performance Management/Appraisal and the contributions of Human Resource Planning to organisations.

\section{Materials and Methods}

\subsection{The Study Area}

Asuogyaman District Assembly forms part of the twenty six (26) Municipalities and Districts in the Eastern Region of Ghana it covers a total estimated surface area of 1,507 square kilometers and constitutes $5.7 \%$ of the total area of Eastern Region. The Administrative capital of the District is Atimpoku. The District shares boundaries with Lower Manya
Krobo District and Upper Manya Krobo District to the west respectively, to the east with North Tongu District, to the north with Afram Plains South and to the south with Dangme West District (Ministry of Local Government, 2006).

The population of Asuogyaman District stands at approximately 80,529 people. The district has been divided into two by the Volta Lake (the largest man-made lake in the world). Numerous chains of mountains covered with thick and green vegetation create a serene environment along the banks of the Volta River, and as a result, most of the resort centers are located along the banks of the river. Another natural feature of interest is the existence of a number of islands which attract numerous tourists to the district. Fish farming on a large scale and water sports are great potentials because of the presence of the Volta Lake. Indeed the serene atmosphere created by the Volta River Dam with a lot of Islands coupled with heavily forested chains of mountains is great potentials for investment in tourism. The Volta River in relation to Akosombo, performs local government functions conferred on the District Assembly including rating, licensing and fee-charging except that the District Assembly exercises political authority over Akosombo (Ministry of Local Government, 2006).

\subsection{Research Design}

The design focused on gathering information on contributions of HRD to organisations. The Purposive sampling technique was adopted to select respondents of all categories of staff. This was due to the fact that the questionnaire was given to specific staff who fulfilled the specific requirements of being at a particular positional level within their organization. The research involved collecting data through the administration of a questionnaire. Out of 60 staff, 45 people were given the questionnaire of which 40 returned theirs. These were made up of the management staff, senior staff and junior staff in proportions of $5 \%, 60 \%$ and $35 \%$ respectively.

Each questionnaire was in two parts; the first part of the questionnaire collected demographic data such as sex, age, level of education and length of service of staff. The second part consisted of questions to elicit information from staff as to whether training and development are key motivating tools, ways in which training needs assessments are useful in human resource development, how human resource planning is important in organisations, whether performance management/appraisal is essential in human resource development and their constraints as well as whether human resource development will contribute to increased productivity.

\section{Results and Discussion}

\subsection{Demography of Respondents}

On sex of the respondents, $75 \%$ were males whilst females formed the remaining $25 \%$. This shows the dominance of the males in this organization. It could be observed that the 
educational background of respondents ranged from Elementary/Basic (15\%), Secondary/Commercial/Technical $(27.5 \%)$, to Tertiary $(57.5 \%)$. This suggests that the educational characteristics as it were of the respondents were good as nearly 50 percent of the respondents had higher education (Table 1).

Many of the respondents or half of them to be precise were aged from 20-30 (50\%). The rest aged from 41-50 (30\%), 31$40(17.5 \%)$, and $51-60$ age group formed $2.5 \%$. This means half of the total staff form the active working population and are capable of contributing meaningfully to productivity when properly exposed to training and development (Table 1).

In addition it has been indicated in Table 1 that many of the respondents have spent $1-5$ years $(67.5 \%)$. Others have spent $16-20$ years $(22.5 \%), 11-15$ years $(7.5 \%)$ and lastly 36 40 years formed $2.5 \%$ all of the total number of staff that were sampled for the study.

Table 1. Summary of demography of the respondents.

\begin{tabular}{lll}
\hline Demographic variable & Frequency & Percentage \\
\hline Sex & 30 & \\
Male & 10 & 75.0 \\
Female & & 25.0 \\
Educational level & 6 & \\
Elementary/Basic & 11 & 15.0 \\
Secondary/Commercial/Technical & 23 & 27.5 \\
Tertiary & & 57.5 \\
Age groups & 20 & \\
20-30 & 7 & 50.0 \\
$31-40$ & 12 & 17.5 \\
$41-50$ & 1 & 30.0 \\
$51-60$ & & 2.5 \\
Years of service & 27 & \\
$1-5$ & 3 & 67.5 \\
11-15 & 9 & 7.5 \\
16-20 & 1 & 22.5 \\
$36-40$ & 3 & 2.5 \\
Structure of respondents & & \\
Senior staff & 24 & 60.0 \\
Management staff & 13 & 32.5 \\
Junior staff & 3.5 \\
\hline
\end{tabular}

\subsection{The Contribution of Human Resource Development to Productivity in Organizations}

All the respondents $(100 \%)$ were of the view that HRD will lead to efficiency on the job giving reasons that, it will lead to staff efficiency $(32.5 \%)$, increase productivity $(30.0 \%)$, allows the worker to perform creditably $(12.5 \%)$, employees will develop new skills (12.5\%), decreases employee turnover $(7.5 \%)$ and, last, builds good public support $(5.0 \%)$. Organisations should therefore see the need to develop their human resource base at all times to promote efficiency on the job.

Of interest to the study was also the need to find out if HRD can contribute to increased productivity. All the respondents agreed to this, pointing out that it leads to higher performance and productivity (50.0\%) fosters career development $(32.5 \%)$ and also caters for individual career planning $(17.5 \%)$. This leaves no doubts that human resource development helps organisations to achieve their ultimate aim of higher productivity. This is supported by the view of Acheampong (2000) that training is an important investment in human resources since it increases employee's productivity.

The respondents suggested the following ways to improve HRD in organizations: there should be series of training $(25.0 \%)$, there should be enough financial resources $(22.5 \%)$, all staff should be given the chance to train $(15.0 \%)$, staff should be well motivated (12.5\%), hard working workers should be rewarded (12.5\%), there should be equal training to all staff $(7.5 \%)$ and finally there should be enough physical resources $(5.0 \%)$.

\subsection{The Contributions of Performance Management or Appraisal to Organisations}

On the issue of whether performance management/appraisal is important to human resource development majority of the respondents $(90.0 \%)$ were of the view that it was important whilst the rest $(10.0 \%)$ said no it was not so.

Reasons were given to buttress why performance appraisal is important. These include providing a basis for promotion $(55.0 \%)$, as an indicator of how employees are performing $(20.0 \%)$, non-performing workers will be motivated to work harder $(15 \%)$. However, $10 \%$ did not assign any reasons. The implication here is that it will be impossible to rule out performance management in human resource development as emphasized in the view of Invancevich (2001) that performance appraisal is a human resource management activity that is used to determine the extent to which an employee is performing the job assigned to him effectively.

Many of the respondents were of the view that there are constraints to performance management/ appraisal (75\%), with some identified to be officers unwillingness to do it $(30 \%)$, element of subjectivity $(17.5 \%)$, time constraint $(12.5 \%)$, it is cumbersome $(12.5 \%)$, and lastly inadequate appraisal materials $(2.5 \%)$. This suggests that performance management/appraisal could be improved if these barriers are removed.

\subsection{The Contributions of Human Resource Planning to Organisations}

On the importance of human resource planning, all the respondents $(100.0 \%)$ overwhelmingly answered on the affirmative with the reasons being that planning helps to prepare for the future $(35.0 \%)$, increases productivity $(25.0 \%)$, planning is important in any management work $(17.5 \%)$, helps the organisation employ the right calibre of staff $(12.5 \%)$ and finally it helps the organisation to achieve its objectives (10.0\%). This supports the claim of Snell et al (2001) that the purpose of human resource planning is to deploy human resources as effectively as possible, where and 
when they are needed in order to accomplish the organisation's goals.

Some of the constraints to the human resource planning process are seen in Table 2 .

These include budgetary constraints (37.5\%), social pressure to provide the right environment $(20.0 \%)$, lack of learning materials $(12.5 \%)$ and Technological constraints (5.0\%). 25\% did not respond at all.

Table 2. Some constraints to human resource planning.

\begin{tabular}{lll}
\hline Responses & Frequency & Percent \\
\hline & 10 & 25.0 \\
Technological constraints & 2 & 5.0 \\
Budgetary constraints & 15 & 37.5 \\
Social pressure to provide the right environment & 8 & 20.0 \\
Lack of learning materials & 5 & 12.5 \\
Total & 40 & 100.0 \\
\hline
\end{tabular}

Source: Field work, 2009

\section{Conclusion and Recommendations}

\subsection{Conclusion}

Based on the findings, it can be concluded that;

Majority of staff in the Asuogyaman District Assembly were occasionally involved in a training programme, with some never engaged in any form of training; but since staff were motivated, confident, very happy and ready to work after training, it must be encouraged. Again, without training and development, productivity in general will be low and will lead to a lot of inefficiencies and retard development (Walmsley, 2005). This is in respect of all the respondents $(100 \%)$ view that training serves as a source of motivation and increases productivity.

- All the respondents $(100 \%)$ were of the view that human resource planning is important in any management work and helps organisations to achieve their objectives. Moreover, organisations are able to employ the right caliber of staff and promote planning for the future (Vetter, 1969). Additionally, it ensures that the resources required for their production in the foreseeable future are uptimalised and also to facilitate the identification of ways of making them more flexible as well as improvement and retention of staff.

Thus Appraisal offers a valuable opportunity to focus on work activities and goals, to identify and correct existing problems, and to encourage better future performance. This in effect serves as a data base which can be used to monitor the success of the organisation's recruitment, induction and training practice thereby linking them to performance outcomes and future aspirations. Dulewicz (1989).

The study found all the staff (100\%) agreeing to the fact that human resource development leads to efficiency on the job, decreases employee turnover and promotes increased productivity. It makes well trained staff competitive and equips them with the needed knowledge and skills to make the desired impact. In other words it promotes the development of new knowledge, skills, and improved behaviours that results in performance enhancement and improvement related to one's current job and identifying performance breakdowns within an organisational system and adopting appropriate interventions useful in achieving the desired performance results (Cascio, 1992).

\subsection{Recommendations}

The findings and conclusions from the study have certain implications for individual career development, organizational development, human resource planning and management procedures that will help organisations and policy makers to make informed decisions about the overall contributions of human resource development to organisations. Below are some of the recommendations that came out as a result of the study.

- The importance of human resource planning cannot be over emphasized and must be carried out by all organisations. It must be undertaken to promote other activities of the organisation such as budgeting, recruitment, selection, transfer, training and development. This recommendation is backed by $100 \%$ view of the respondents that planning helps to prepare for the future and makes it easier for the organisation to achieve its objectives. This is however in response to recent major changes in business, economic and social environments full of uncertainties hence forcing organisations to integrate business planning with human resource planning to adopt a longer term measure.

- As indicated by $90 \%$ of the respondents, performance management/appraisal is useful and must be carried out transparently. It should be periodically done to provide information or feedback that will enable the individual to improve his or her performance and develop his/her potential for the benefit of the organisation.

- That is, revealing the employee's strengths and weaknesses for appropriate remedial actions. Also, if nothing else, the existence of an appraisal programme will indicate to an employee that the organisation is genuinely interested in their individual performance and development. This alone can have a positive influence on the individual's sense of worth, commitment and belonging.

- All organisations should have human resource development policy that will encourage the utilization of learning, performance and change as a means to increase productivity and improve performance. Again, all human resource development activities should be carefully planned with their cost implications also considered and the decisions based on cost effectiveness. This is in line with the views of all the respondents $(100 \%)$ within the study that human resource development caters for individual career planning and fosters career development which leads to higher performance and productivity, leading to increased competitiveness of the organisation. 


\section{References}

[1] Acheampong, I. K. (2006). Human Resource Development: Labour market concepts and operations. Catholic Mission Press: Cape coast.

[2] Snell, S. A., Morris, S. S. \& Bolander, (2001). Managing human resources. New York: South-Western College Publishing.

[3] Cascio, W. F (1992). Managing Human Resources. U.S.A: McGraw-Hill.

[4] Dulewicz, V. (1989). Performance Appraisal and Counselling. In Herriot, P. Assessment and Selection in Organisations: methods and practices for recruitment and appraisal (Pp. 645649). New York: John Willey and Sons.

[5] Dyer, L. (2006). Bringing human resources into the strategy formulation process. Human Resource Management, 22 (3): 257-257.

[6] Jennine K. (2015), Investing in Human Resource
Development: Strategic Planning for Success in Academic Libraries, in Delmus E. Williams, Janine Golden, Jennifer K. Sweeney (ed.) Advances in Library Administration and Organization (Advances in Library Administration and Organization, Volume 33) Emerald Group Publishing Limited, pp. 1-42.

[7] Ministry of Local Government. (2006). Asuogyaman District Assembly, Ghana. Retrived on $3^{\text {rd }}$ February, 2015 from http://www.ghanadistricts.com/districts/?r=2\&=21\&sa4538

[8] Nadler, L., \& Wiggs, G. (1986). Managing Human Resource: A Practical Guide. San Francisco: Jossey-Bass.

[9] Noe, R. A., Hollenbeck, J. R., Gerhart, B., \& Wright, P. M. (2014). Human Resource Management; Gaining a competitive advantage, $9^{\text {th }}$ edn. New York: Irwin/McGraw-Hill.

[10] Vetter, E. W., (1967). Manpower Planning for high talent Personnel. Ann Arbor: University of Michigan, GraduateSchool of Business, Bureau of Industrial Relations.

[11] Walmsley, B. (2005). Teach yourself training; Hodder Arnold. London. 